\title{
Microstructure Development in Powder Bed Additive Manufacturing.
}

\author{
John Porter ${ }^{1}$, Michael Velez ${ }^{1}$, Brian Hayes ${ }^{1}$, Heather McCrabb $^{2}$ and Tim Hall ${ }^{2}$ \\ 1. UES Inc., Dayton, OH, USA \\ 2. Faraday Technology Inc., Englewood, OH, USA
}

Powder bed methods of additive manufacturing (AM) use either an electron beam (Electron Beam Melting - EBM) or a laser (Selective Beam Melting - SLM) to sequentially melt powder, layer by layer, to build up a 3-dimensional object directly from a powder bed according to a computer aided design (CAD) file. Complexity is free with AM processes, so parts such as the impeller shown in Figure 1, are natural candidates for AM.

With EBM. there are four steps to create each layer in a build. First, the beam is scanned to preheat the powder bed without melting, second, the contours (outer edge) of the area to be melted is traced and powder melted, third, the hatch (area within the contours) is melted and finally any supports that need to be built to support higher layers of the part being built are added. The side face of a part adjacent to powder after an EBM build is shown in Figure 2.

With SLM, a similar strategy is used although powder bed preheating is not necessary (the powder bed remains at ambient temperature or is preheated to a low temperature - up to $200^{\circ} \mathrm{C}$ - with separate heaters). The result of this low temperature processing is that residual stresses are created. The supports which are added to the model to support higher level downward facing surfaces are structural in nature and used to prevent distortion (unlike those supports in the EBM process which are added for thermal management).

In each process, a melted layer fuses with the underlying layers and each layer can grow epitaxially on the layer below, resulting in columnar grains, $\mathrm{mm}$ in dimension, elongated in the growth direction. Figure 3 shows Ti 6Al 4V (EBM) as an SEM/EBSD image pair, Figure 4 shows the same for IN718 (SLM).

The major concerns for incorporation of AM into structural parts are (1) microstructural anisotropy/inhomogeneity, (2) porosity - open near the surface and closed internally and (3) surface finish that is strongly dependent on the orientation of the surface relative to the build direction.

Closed porosity can be eliminated through hot isostatic pressing (HIP) and parts can require a heat treatment, e.g. for IN718. However, the potential for on demand manufacturing in remote locations may preclude the possibility of HIP and therefore an understanding of porosity development is important.

Improving surface finish is critical for certain applications. While finish machining can be used where surfaces are accessible, one benefit of the complexity of part shape is the possibility of building parts with internal channels, inaccessible to machining. Here we are using electrochemical finishing approaches to create internal channels with a controlled surface roughness.

Figure 5 shows the surface roughness reduction on a $\mathrm{Ti} 6 \mathrm{Al} 4 \mathrm{~V}$ coupon after electrochemical finishing of an as-built surface that was built parallel to the growth direction. The Ra reduction was from $16 \mu \mathrm{m}$ 
to $<2 \mu \mathrm{m}$, after $550 \mu \mathrm{m}$ of material had been removed.

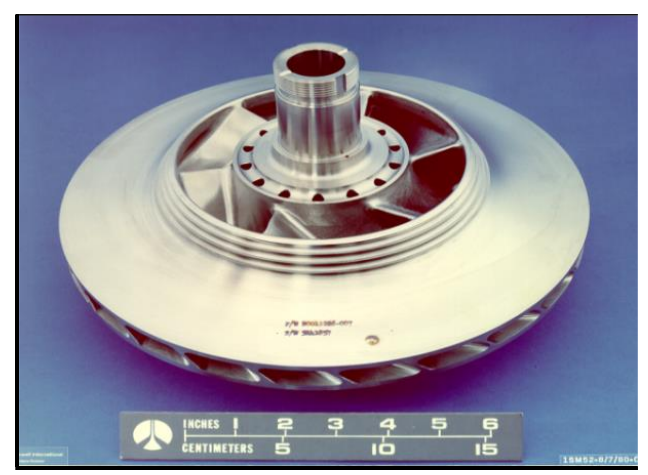

Figure 1. Impeller
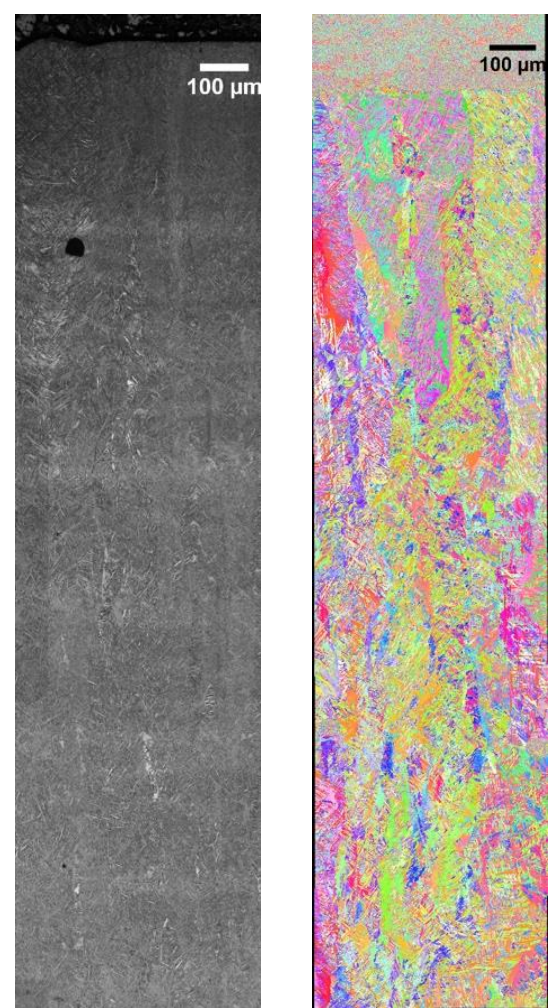

Figure 3. SEM/EBSD pair Ti $6 \mathrm{Al} 4 \mathrm{~V}$

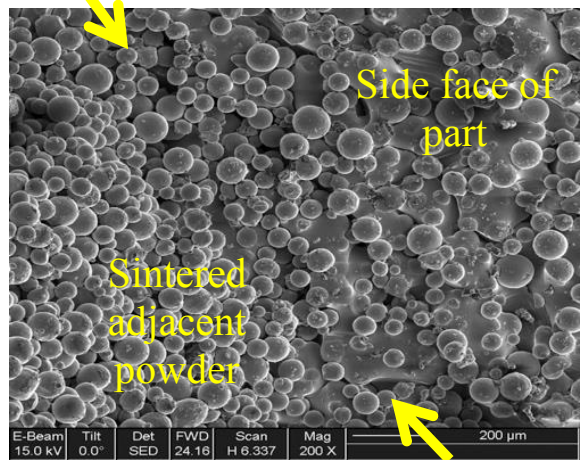

Figure 2. Side face of part - Ti $6 \mathrm{Al} 4 \mathrm{~V}$
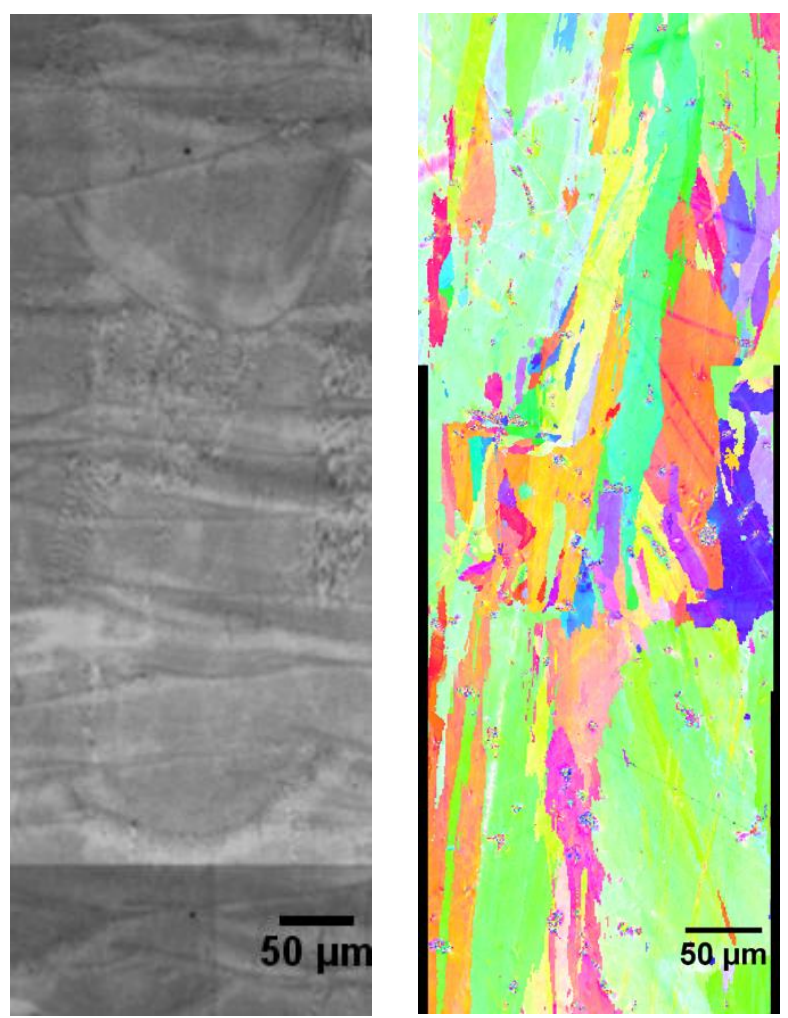

Figure 4. SEM/EBSD pair IN718

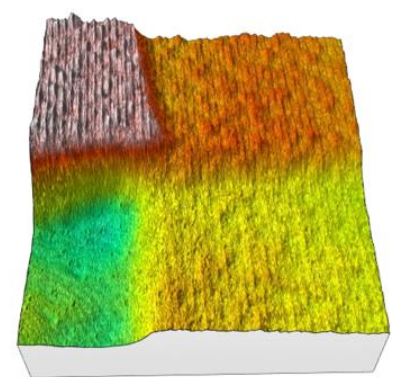

Figure 5. Electrofinished surface of $\mathrm{Ti} 6 \mathrm{Al} 4 \mathrm{~V}$ showing reduction in surface roughness. 